\title{
“Unutma Beni” Filminin Kimlik Kaybı ve Muğlak \\ Kayıp Çerçevesinde İncelenmesi
}

\author{
Ece Bekaroğlu \\ Gazi Üniversitesi \\ Edebiyat Fakültesi \\ Psikoloji Bölümü
}

\begin{abstract}
ÖZ
Unutma Beni filmi Dilbilimi Bölümü'nde profesör olan Alice Howland'ın erken başlangıçlı Alzheimer teşhisi alma deneyimini, bu deneyimin kendisi üzerindeki etkilerini ve ailesi ile ilişkilerini etkileme şekillerini ele alır. 50. yaş gününden birkaç gün sonra kelimeleri hatırlayamama ve yolda kaybolma gibi şikayetlerle nöroloğa giden Alice, detaylı incelemeler ardından nadir olarak görülen aileden gelen erken başlangıçlı Alzheimer teşhisi alır. Teşhisin ardından çocuklarının da bu hastalığı geliştirme riski olduğunu öğrenir ve eşiyle birlikte bu tanıyı çocuklarına açıklar. Bir süre sonra Alzheimer sebebiyle Alice işine devam edemez, sürekli bakım verecek birine ihtiyaç duymaya başlar. Bu süreçte Alice'in kimliğini sorguladı̆̆ı, ailesinin de fiziksel olarak var olan bir aile üyesinin psikolojik kaybıyla farklı şekillerde baş etmeye çalıştı̆̆ görülür. Film, Alice'in Alzheimer sebebiyle yaşadığı kimlik kaybı ve ailesinin bu hastalık karşısında yaşadığı muğlak kayıpları ile baş etme yolları üzerinden ele alınmıştır.
\end{abstract}

Anahtar Kelimeler: Unutma Beni filmi, Alzheimer, Kimlik kaybı, Muğlak kayıp

Gazi Üniversitesi Psikoloji Bölümü

İletişim: ecetathan@gmail.com

Gönderim Tarihi: 10.01.2015

Kabul Tarihi: 04.02.2016 


\section{Abstract \\ The Analysis of the Movie "Still Alice" within the Scope of Identity Loss and Ambiguous Loss}

The movie "Still Alice" discusses Alice Howland's, a linguistics professor, experience of early onset Alzheimer disease, and the effects of this disease on her life and relationships with her family. After the celebration of her 50th birthday, Alice goes to a doctor due to the problems of forgetting words and becoming lost on the campus. After detailed investigations, neurologist diagnoses her with early onset familial Alzheimer's disease. With the diagnosis, she realizes that her children have the same risks of developing Alzheimer's disease. Thus, with her husband, she explains her diagnosis to her children and their risks of development of the same disease. After a while, she losses her job and needs a caregiver.

Throughout this process, while Alice questions her identity, her family tries to cope with psychological loss of a loved one when she is physically present. Alice's loss of identity and ambiguous loss of her family because of Alzheimer's disease is discussed within the scope of the movie.

Keywords: Still Alice movie, Alzheimer's disease, Identity loss, Ambiguous loss 


\section{"Unutma Beni" Filminin Kimlik Kaybı ve Muğlak Kayıp Çerçevesinde İncelenmesi}

\section{Filmin Künyesi}

Filmin Adı: Still Alice-Unutma Beni

Yönetmenin Adı: Richard Galtzer ve Wash Westmoreland

Oyuncular: Julianne Moore, Kristen Stewart, Kate Bosworth, Alec Baldwin, Hunter Parrish

Yapım Y111: 2014

\section{Filmin Konusu}

Unutma Beni filmi, Columbia Üniversitesi Dilbilimi Bölümü'nde profesör olan Alice Howland'ın (Julianne Moore) bazı kavramları unutmasıyla başlayan erken başlangıçlı Alzheimer hastalığı deneyimini ve bu deneyimin kendisini ve ailesini etkileme şekillerini ele alır.

Alice ailesiyle birlikte kutladığ 1 50. yaş gününün ardından, konuk olarak gittiği bir üniversitede yaptığı konuşmada, çalışma alanıyla ilgili bir kelimeyi unuttuğunu fark eder, ardından yıllardır ders verdiği kampüste yolunu kaybeder. Belirtilerin ardından nöroloğa başvurur, yapılan testlerin ve değerlendirmelerin ardından kendisine aileden gelen genetik faktörlere bağlı olan erken başlangıçlı Alzheimer tanısı konulur. Doktoruna ebeveynlerinde bu tanının görülmediğini anlatırken, annesini kız kardeşiyle birlikte bir trafik kazasında kaybettiğini belirtir ancak alkol bağımlılığı sebebiyle ölen ve uzun yıllar görüşmediği babasında da benzer semptomların olduğunu fark eder. Ailesel faktörlere bağlı olması sebebiyle üç çocuğunun da bu hastalığın riskini taşıdığını öğrenir, çocuklarına rahatsızlığını anlatır ve onların da hastalığın risk grubunda olduğunu açıklar. En büyük çocuğu Anna (Kate Bosworth) genetik testi yaptırır ve kendisinde de bu genin olduğunu, bu sebeple de hastalığı geliştireceğini öğrenir. Ortanca çocuğu Tom'da (Hunter Parrish) bu gen çıkmaz, en küçük çocuğu Lydia (Kristen Stewart) ise testi yaptırmayı reddeder. Alice hastalığının oldukça ilerlemesi riskine karşı telefonuna kendisinin kolayca cevaplayabileceği sorular yazar, bu soruları cevaplayamayacağı duruma gelmesi halinde kendisi için kaydettiği bir videoyu izlemesi gerektiğini belirtir. Video kendisini uyku haplarıyla intihar etmeye yönlendirecek bir videodur. Hastalığı ilerledikçe üniversitedeki derslerini etkin bir şekilde işleyemez ve işini kaybeder. Evinde banyonun yerini bulamaz ve kızı Lydia'nin bir tiyatro oyunundaki performansından sonra kızını tanıyamaz. Bu zorluklara rağmen deneyimlerini Alzheimer konferansında konuşma yaparak paylaşır. Bir gün telefonunu kaybeder, zamanla unutacağı her bilgiyi telefonuna kaydettiği için panikler, eşi telefonu bir ay sonra buzlukta bulur ancak Alice sadece 1 gün geçtiğini düşünmektedir. Kızıyla internet üzerinden yaptığı bir görüşmenin ardından yanlışlıkla kendisine intihar yönergelerini veren videoyu açar, zorlukla da olsa talimatları yerine getirip ilaçları bulur, ilaçları yutacağı sırada kendisine bakan görevlinin eve gelmesiyle dikkati dağılır ve intihar planını anında unutur. Alice'in eşi John (Alec Baldwin) bu süreçte başka bir şehirde iş teklifi alır, Alice tanıdığı ortamdan ayrılmasının hastalığı için iyi olmadığını söyleyerek iş teklifini bir süre ertelemesini ister ancak John bunun imkansız olduğunu söyleyerek taşınır. John taşınırken Alice ile ilgilenmesi için en küçük çocuğu Lydia eve geri döner. Lydia annesine tiyatrodaki rolünden bir bölüm okur ve Alice'e ne düşündüğünü sorar, artık zorlukla konuşan Alice ise tek bir kelime ile cevap verebilir, o da sevgidir.

\section{Alice'in Penceresinden: Alzheimer ve Kimlik Kaybı}

Filozof Husserl'a göre kendilik, kişinin kendinde ne gördüğü, kendiyle ilgili ne hatırladığı ve neyi hatırlamayı seçtiği ile beslenir (aktaran Eustache ve ark., 2013). Psikoloji alanında kendiliğin, hafızadaki kendilik temsillerinin yapısal düzeyleriyle ilişkili karmaşık boyutlardan oluştuğu (Kihlstrom, Beer, ve Klein, 
2002) ve hafızadaki kendilik temsillerinin kimlik oluşumunu sağladığı (Klein, 2010) belirtilir. Eğer kişi kendilik temsillerini kaydettiği hafizası ile ilgili bir problem yaşarsa neler olur? Addis ve Tippett (2004) yaptıkları araştırmada, hafif ve orta düzeyde demansı olan Alzheimer hastalarının kontrol grubuna göre daha zayıf ve belirsiz bir kimlik algıları olduğunu ve kimlik algılarının kalite ve gücünün, çocukluk ve erken yetişkinlik dönemleri ile ilgili otobiyografik hafızalarındaki bozulmalar sebebiyle olduğunu belirtmişlerdir. Alice bebeklerin kelimeleri nasıl öğrendiği sürecine odaklanan bir kariyerin ardından, kelimelerini kaybeder. Kelimeleri, randevuları ve insanları unutmaya başlamasının ardından Alzheimer yerine kanser olmayı diler ve büyük bir utanç yaşamaya başlar. Yıllardır emek verdiği mesleğinin ardından tek yatırımı olan hafızasının kaybı karşısında yaşadığı hayal kırıklığı ve çaresizliği gözlemlenebilir. Bu utancın bir üst katmanında genellikle öfkesi ve hatırlayamadığı için kendisine olan kızgınlığı hissedilir. Alzheimer derneğinde yaptığ konuşmasında ise bir zamanlar olduğu kişiden bu kadar uzaklaştığında kendisini kimin ciddiye alabileceğini sorgular. Özetle filmde, kişinin kendilik temsillerini ve kimlik algısını kaybetmesi büyük bir hayal kırıklığının ardından utanç ve öfke gibi olumsuz duygularla ifade bulur.

Film süresince Alice'in çocukluk dönemine ait bir anısı gösterilir. Bu anıda trafik kazasında kaybettiği annesi ve kız kardeşi ile birlikte kumsalda yürüyüş yaptıkları ve çok mutlu oldukları görülür. Babasına ise alkol bağımlılığı sebebiyle öfkeli olduğu, bu anılarda ona yer vermediği halde, zamanla anılarında babasını da kumsaldaki o mutlu güne dahil ettiği fark edilir. Kimlik algısına katkı sağlayan anılardan birine yapılan bu gönderme, filmin sonunda Alice'in bu anıyı da hafizasında kaybetmesi ile sonlanır. Otobiyografik hafızadaki bu önemli anının kaybı ile seyircilere Alice'in kimliğini daha da kaybettiği izlenimi verilir.

İş yerinden ayrılması ve rutininden uzaklaşması ile yaşadığı kayıpların ardından eşiyle yaptıkları bir seyahatte Alice annesinden kendisine kalan kelebek şeklinde bir kolyeyi fark edip, kolyeyi takmaya başlar. Kızı Lydia'ya, annesinin kelebeklerin ömrünün kısa olduğu halde, güzel bir hayat yaşadıklarını söylediğini anlatır. Bir kelebeğin kozasından çıkıp özgürleştiği, uçmaya başladığı bir süreç gibi, Alice de iş hayatında en üretken olduğu ve ailesine önemli destekler sağlayabileceği bir dönemde hafizasını kaybederek, özgürlüğünü sağlayan "kanatlarının" kaybını yaşar. Annesinin ve kız kardeşinin erken yaşlarda kaybının yasını ve beklenmedik bir zamanda kendi kimliğinin kaybının yasını, kısa ama güzel geçen yılların kabulünü bu kelebek kolye üzerinden de tamamlamaya çalıştığı düşünülebilir.

Erikson'a göre insan yaşamı boyunca belirli psikososyal evrelerden geçer. Kişi 40 ve 65 yaş arasındayken, üretkenlik ile durgunluğun çatıştı̆̆ bir evrededir. Üretkenlikte kişi ailesi ve ailesi ötesindeki kuşaklar, toplum ve dünya ile ilgilidir. Yani kişi dünyayı daha iyi bir hale getirmek için neler yapabileceği ve gelecek kuşaklara neler aktarabileceği ile uğraş halindedir. Eğer kişi durgunluk deneyimliyorsa, kendi gereksinimlerine odaklanıp dünya ve gelecek nesillere ilgisiz kalır (Erikson, 1963; Elkind, 1970).

Alice'in Erikson'un teorisine göre bulunduğu psikososyal evrede bir kelebek gibi kanat çırparak uzun süreli yatırımlarının sonucunu alabileceği, üretkenlik deneyimleyeceği bir yol izlerken Alzheimer ile ketlendiği belirtilebilir. Üniversitede öğretim elemanı olmasının bu üretkenliği getirmesinin yanı sıra, yaşı gereği torunlarının dünyaya geldiği, bilgi ve deneyimlerini çocuklarına ve torunlarına aktarabileceği bir süreçte hafızasını yitirmesi gelecek nesillere bu kıymetli verilerin aktarılmasını engellemektedir. Çalıştığ bilim alanıyla da paralel bir şekilde kendisini zihniyle, sözleriyle, konuştuklarıyla tanımlayan bir kişinin sözcüklere ulaşamayıp, ifade yeteneğini kaybetmesi, kendi arzusuyla olmasa da kendi gereksinimlerine odaklanmasına sebep olup gelecek nesillere bilgi aktaramamasına sebep olur.

\section{Alice'in Ailesinin Penceresinden: Alzheimer Hastası Yakınları ve Kayıp}

Gözlemlenebilen ve olağan bir şekilde yaşanan en büyük kayıp ölümdür ve bu olay ölüm belgesi, cenaze ritüelleri gibi olaylarla da onaylanır. Ölüm durumunda kişiler kalıcı bir kaybın olduğunu ve yas sürecinin 
başlayacağını öngörebilirler. Ancak daha karmaşık bir yas süreci olan muğlak yas, psikolojik olarak aile içinde var olan bireylerin fiziksel olarak yokluğunda (kayıp asker, kaçırılan çocuklar) veya fiziksel olarak aile içinde var olan bireylerin psikolojik olarak yokluğunda (Alzheimer hastalığı, bağımlılık) yaşanan normal dışı bir kayıp olarak açıklanır (Boss, 1999). Alzheimer hastasının bellek ve beceri kaybı ile birlikte hasta yakını hastayla yaşadığı anıların kaybı karşısında kendisini uzun bir yas sürecinin içinde bulabilir yani hastayı tamamen kaybetmeden önce yaşanan kayıplarla birlikte uzun ve muğlak bir yas sürecinden bahsetmek mümkündür. Alzheimer hastasının varlığı ya da yokluğu ile ilgili olarak belirsizlik ne kadar fazlaysa, ailedeki depresyon semptomlarının da o seviyede arttığı belirtilmiştir. Muğlak kayıp hasta yakınlarında kronik psikolojik rahatsılıklara sebep olduğu gibi günlük hayatta yakınına karşı belirsiz bir vedaya da sebep olabilir. Bu belirsiz vedaya verilen en yaygın tepki ise iş ile oldukça yoğun bir şekilde uğraşmaktır. Hasta yakınları obsesif bir şekilde işleri ile meşgul oldukça, Alzheimer hastalarının yanlarında olamazlar (Boss, 1999).

Alice'in ailesi de fiziksel olarak hala yanlarında olan bir kişinin kimliğinin kaybı ile yüzleşerek normal dışı bir yas süreci deneyimlemektedirler. Bu muğlak kayıp ve yas süresinde özellikle eşinin farklı savunma mekanizmaları kullanması dikkat çekmektedir. Alice'in Alzheimer tanısı şüphesini paylaştığı sırada, eşi John anlattığı belirtilerin yaşının ilerlemesi ile ilgili olduğunu, kendisinin de unutkanlıkları olduğunu ve olayı abarttığını söylemektedir. Acı verici bir deneyim ya da felakete verilen ilk tepki olan inkar, bu zorlu deneyimle başa çıkmak için verilen ilk tepki olabilir (McWilliams, 2010). Bu savunma mekanizmasının temelinde ilkel bir düzeyde olayı kabul etmezsem olmamış olur düşüncesi yer alır. Ardından John, Alice ile birlikte test sonuçlarını öğrenmek için doktora gider. Test sonuçları ve değerlendirmeler erken başlangıçlı Alzheimer tanısını göstermektedir. John tanıyı duyan hasta yakınının yaşayacağı duygular yerine, bu tanıyı ve tanı kriterlerini sorgular. Burada da John'un yaşadığı kaygı, üzüntü gibi duygularla baş etmek için, yaşadığı deneyimin duygusal yönünü soyutlayarak sadece bilişsel boyutu ile deneyimlediğini yani yalıtma savunma mekanizmasını kullandığı belirtilebilir (McWilliams, 2010). John tanının ardından Alice ile zaman geçirip, yanında olmaya çalışsa da süreç içerisinde işi ile yoğun bir şekilde uğraşmaya başlar. Alzheimer hastası yakınlarının yaşadığı muğlak yas ile baş etmek için kullandıkları bir yöntem olan işe yoğunlaşma John'un da baş etme mekanizması olarak gözlemlenebilir. İşe yoğunlaşmasının ardından başka bir şehirden aldığg iş teklifini kabul etmek isteyen John'a, Alice taşınmalarının kendisine iyi gelmeyeceğini söyleyerek karşı çıkar. Burada Alice'e destek olup onun yanında olmak yerine kendilerini geçindirmek için çalışması gerektiğini söyleyen John, rasyonalizasyon (akılcılaştırma) savunma mekanizmasını kullanıyor olabilir. Bu savunma mekanizması kişinin güç bir durumla en az zararla başa çıkması için kullanılır. İnsanların zorlu olaylar ardından duyguları ile karar verdiklerini söylemek yerine daha kabul edilebilir iyi nedenlerle hareket ettiklerini açıklamaları bu savunma mekanizmasına örnek olarak verilebilir (McWilliams, 2010). Yaşadığı zorlu duygularla baş edemeyip, ortamdan uzaklaşmak istemesini ya da kariyerini ön plana almasını haklı çıkarmak adına, John'un kendilerini geçindirmek için gitmesi gerektiğini söylemesi aslında mantığa uygun açıklamalar üreterek, verdiği kararı makul gösterme çabasıdır.

John gitmeden önce çocukları Anna ve Tom ile taşınma ardından oluşacak süreç ile ilgili görüşür. Bu sohbet esnasında Alice yanlarında uyukluyorken onun hakkında aslında geçmiş zaman kipiyle, onu çoktan kaybetmişler gibi konuştukları fark edilir. Muğlak yas sürecinde karmaşık duygular bir arada yaşanabilir, aynı kişiye sevgi ve nefret ya da kabul ve red aynı anda hissedilebilir, kaybın inkar edilmesi ya da kabulü aynı anda deneyimlenebilir (Boss, 1999). Bu sahnede de Alzheimer ile birlikte gelen muğlak yas sonucunda John ve çocukların hem Alice'in kaybını hem de varlığını aynı anda deneyimledikleri gözlemlenebilir. Muğlak yas sürecinde çocuklar anne nesnesinin kaybının yanı sıra, değişen rollerle de baş etmek durumunda kalır. 
Winnicott (2010) annenin bebeğine ayna işlevinde bulunduğunu, bebeğin annenin yüzünden aldığı geri bildirimlerle nasıl göründüğünü ve kendisini nasıl algılayacağını öğrendiğini belirtir. İnsanın aynaya bakıp kendisini incelediği gibi, bebek de annesinin ona nasıl baktığını kendisini aynada izliyormuş gibi izler. Muğlak yas sürecinde annesinden aynalanan bir çocuğun anne nesnesini kaybettiği, yani Alzheimer hastasının, çocuğunu bir anne nesnesi olarak aynalayamadığı hatta çocuğun zamanla ayna nesnesi olup hastayı aynaladığı, böylece rollerin değiştiği söylenebilir (Özalkuş-Şahin, n.d.). Alice'in çocuklarının da anne nesnelerini kaybettikleri ve aile içerisindeki rolleri yeniden oluşturmaya çalıştıkları belirtilebilir. Alice'in kızı Lydia'nın mesleki kariyeri ile ilgili kaygıları olduğu ve onunla bu konuda sıklıkla konuştuğu gözlemlenirken, John'un evden taşınmasının ardından kızı Lydia'nın Alice'in annesi rolüne geçtiği, onun için kaygılandığı ve onu anlayabilmek için konuşmayı öğrenmemiş bir bebeğin anne ile aynalandığı gibi Alice'i aynalamaya çalıştı̆ğ söylenebilir. Burada üç çocuk için de anne nesnesinin kaybı mevcuttur ancak yeni ilişki rolüne en iyi adapte olan çocuğun Lydia olduğu görülür. Annesinden istediği kabulü elde etmekte zorlanan Lydia'nın annesinin hastalığı sonrasındaki yeni durumunu kolaylıkla kabul etmesi, yıllar boyunca annesinden alamadığı kabulü ona yönlendirerek kabul arzusunu aşırı telafi etmeye çalıştığını düşündürebilir. Erken başlangıçlı Alzheimer geninin kendisinde olup olmadığının belirleneceği testi almayarak belirsizliğe toleransını yüksek tutan Lydia annesinin bakıcısı olarak yeni rollere daha esnek bir şekilde uyum sağlayabilmiştir. Evin en büyük çocuğu Anna ise akademisyen olan ebeveynlerinin beklentilerini karşılayarak onlardan onay alabildiği halde, muhtemelen onay alabilmek için kendi gerçek benliğinden uzaklaştığından daha öfkeli ve eleştirel biri olmuştur. Yıllar boyunca onay almış olan Anna, annesinin hastalığını kabul etmekte ve annesine onay vermekte zorlanmıştır. Oğlu Tom'un ise babasına benzer bir şekilde gittikçe Alice'in hayatından uzaklaştığı ve annesiyle sınırlı bir ilişki kurmaya başladığı görülür.

\section{Sonuç}

Unutma Beni filmi Dilbilimi profesörü olan ve bebeklerin dil öğrenme süreçleri alanında çalışan Alice Howland'in zamanla kelimeleri unutması, yolunu kaybetmesi gibi belirtilerle başlayan Alzheimer hastalığ 1 sürecini anlatmaktadır. Kendisini kelimelerle, konuştuklarıyla, zihniyle tanımlayan ve bu alanda kendisine yatırım yapmış Alice, hastalık sürecinde kim olduğunu hatırlamakta zorlandığını ve hafızasının yanı sıra neleri yitireceğini bilmediği korkusunu yaşadığını anlatır. Alice'in deneyimleri kimlik kaybı ve Erikson'un psikososyal süreçlerine göre üretkenlik çağını yaşamak isteyen birinin durgunluk dönemine sürüklenme deneyimi ile ilişkilendirilebilir. Alice'in eşinin ve çocuklarının Alzheimer hastalığına verdikleri tepkiler ise yakınlarının fiziksel olarak var oldukları halde psikolojik olarak yokluklarında muğlak yas yaşayan hasta yakınlarının tepkileri ile açıklanabilir. Muğlak yasın sonucunda Alice'in eşi John'un kullandığı çeşitli savunma mekanizmaları ve çocuklarının aynalayan anne nesnesi kaybına verdikleri tepkiler ile değişen anne çocuk rolleri ele alınmıştır. 


\section{Kaynaklar}

Addis, D. R., ve Tippett, L. J. (2004). Memory of myself: Autobiographical memory and identity in Alzheimer's disease. Memory, 12, 56-74.

Boss, P. (1999). Ambiguous Loss: Learning to Live with Unresolved Grief. Cambridge, Massachusetts: Harvard University Press.

Elkind, D. (1970). Erik Erikson's eight ages of man. New York Times Magazine, 81-86. Erikson, E. H. (1963). Childhood and Society (2nd ed.). New York:

Norton.

Eustache, M. L., Laisney, M., Justenaite, A., Letortu, O., Platel, H., Eustache, F., ve Desgranges, B. (2013). Sense of identity in advanced Alzheimer's dementia: A cognitive dissociation between sameness and selfhood. Consciousness and Cognition, 22, 1456-1467. Kihlstrom, J. F., Beer, J. S., ve Klein, S. B. (2002). Self and identity as memory. M. R. Leary ve J.

Tangney (Ed), içinde Handbook of self and identity (ss. 68-90). New York: Guilford Press.

Klein, S. B. (2010). The self: As a construct in psychology and neuropsychological evidence for its multiplicity. Cognitive Science, 1, 172-183.

McWilliams, N. (2010). Psikanalitik Tanı: Klinik Süreç Içerisinde Kişilik Yapısını Anlamak (2. Basim).

İstanbul: İstanbul Bilgi Üniversitesi Yayınları.

Özalkuş-Şahin, A. (n.d.). Alzheimer Hasta Yakınları Açısından Nesne Kaybı. Psiko-Alan sitesinden alınmıştır. http://www.psiko-alan.com/makaleler/3-ayse-oezalkus-sahinalzheimer-hasta- yakn-acsndan-nesne-kayb

Winnicott, D. W. (2010). Oyun ve Gerçeklik (3. Basım). İstanbul: Metis Yayınları. 